\title{
Correction to: Awareness and current implementation of drug dosage adjustment by pharmacists in patients with chronic kidney disease in Japan: a web-based survey
}

Yuki Kondo ${ }^{1,2^{*}}$, Yoichi Ishitsuka ${ }^{1}$, Eri Shigemori ${ }^{2}$, Mitsuru Irikura ${ }^{3}$, Daisuke Kadowaki ${ }^{4,5}$, Sumio Hirata ${ }^{4,5}$, Takeshi Maemura ${ }^{2}$ and Tetsumi Irie ${ }^{1,5}$

\section{Correction to: BMC Health Serv Res 14, 615 (2014) https://doi.org/10.1186/s12913-014-0615-0}

Following publication of the original article [1], the authors identified an error in the column $\boldsymbol{p}$ value in Table 5. They erroneously listed the $p$-value for working experience as "0.616", but the correct value is "0.0616". The correct table is given below.

The original article [1] has been updated.

\section{Author details}

${ }^{1}$ Department of Clinical Chemistry and Informatics, Graduate School of Pharmaceutical Sciences, Kumamoto University, 5-1 Oe-honmachi, Chuo-ku, Kumamoto 862-0973, Japan. ${ }^{2}$ Minaminihon Pharmaceutical Center, 5-15-1 Taniyama-chuo, Kagoshima 891-0141, Japan. ${ }^{3}$ Laboratory of Evidence-Based Pharmacotherapy, College of Pharmaceutical Sciences, Daiichi University, 22-1 Tamagawa-cho, Minami-ku, Fukuoka 815-8511, Japan. ${ }^{4}$ Department of Clinical Pharmacology, Faculty of Pharmaceutical Sciences, Kumamoto University, 5-1 Oe-honmachi, Chuo-ku, Kumamoto 862-0973, Japan. ${ }^{5}$ Center for Clinical Pharmaceutical Sciences, Faculty of Pharmaceutical Sciences, Kumamoto University, 5-1 Oe-honmachi, Chuo-ku, Kumamoto 862-0973, Japan.
Published online: 29 June 2021

\section{Reference}

1. Kondo $Y$, et al. Awareness and current implementation of drug dosage adjustment by pharmacists in patients with chronic kidney disease in Japan: a web-based survey. BMC Health Serv Res. 2014;14:615.

The original article can be found online at https://doi.org/10.1186/s12913014-0615-0.

* Correspondence: ykondo@kumamoto-u.ac.jp

1 Department of Clinical Chemistry and Informatics, Graduate School of Pharmaceutical Sciences, Kumamoto University, 5-1 Oe-honmachi, Chuo-ku, Kumamoto 862-0973, Japan

${ }^{2}$ Minaminihon Pharmaceutical Center, 5-15-1 Taniyama-chuo, Kagoshima 891-0141, Japan

Full list of author information is available at the end of the article

C C The Author(s). 2021 Open Access This article is licensed under a Creative Commons Attribution 4.0 International License, which permits use, sharing, adaptation, distribution and reproduction in any medium or format, as long as you give appropriate credit to the original author(s) and the source, provide a link to the Creative Commons licence, and indicate if changes were made. The images or other third party material in this article are included in the article's Creative Commons licence, unless indicated otherwise in a credit line to the material. If material is not included in the article's Creative Commons licence and your intended use is not permitted by statutory regulation or exceeds the permitted use, you will need to obtain permission directly from the copyright holder. To view a copy of this licence, visit http://creativecommons.org/licenses/by/4.0/ The Creative Commons Public Domain Dedication waiver (http://creativecommons.org/publicdomain/zero/1.0/) applies to the data made available in this article, unless otherwise stated in a credit line to the data. 
Table 5 Factors influencing implementation of ADDR by community pharmacists

\begin{tabular}{|c|c|c|c|}
\hline Factor & Odds ratio & 95\% Confidence interval & $p$ value \\
\hline \multicolumn{4}{|l|}{ Routinely receive prescriptions from nephrologists } \\
\hline No & (ref) & $1.16-8.44$ & 0.0247 \\
\hline Yes & 3.12 & & \\
\hline \multicolumn{4}{|l|}{ Experience with adverse drug events caused by inappropriate dosage } \\
\hline No & (ref) & $1.00-15.3$ & 0.0498 \\
\hline Yes & 3.92 & & \\
\hline \multicolumn{4}{|l|}{ Work experience } \\
\hline$<5$ years & (ref) & $0.96-6.02$ & 0.0616 \\
\hline$\geq 5$ years & 2.40 & & \\
\hline Awareness of need for pharmacists to check dosage of renally excreted drugs & 4.44 & $2.52-7.81$ & $<0.001$ \\
\hline
\end{tabular}

Predictors: duration of work experience, Routinely dispense prescriptions from nephrologists, obstacle to implementation of ADDR, awareness of pharmacotherapy for CKD patients 